\title{
Adolescent endogenous sex hormones and breast density in early adulthood
}

\author{
Seungyoun Jung ${ }^{1}$, Brian L. Egleston² ${ }^{2}$ D. Walt Chandler ${ }^{3}$, Linda Van Horn ${ }^{4}$, Nola M. Hylton ${ }^{5}$, Catherine C. Klifa ${ }^{6}$, \\ Norman L. Lasser ${ }^{7}$, Erin S. LeBlanc ${ }^{8}$, Kenneth Paris ${ }^{9}$, John A. Shepherd ${ }^{5}$, Linda G. Snetselaar ${ }^{10}$, Frank Z. Stanczyk ${ }^{11}$, \\ Victor J. Stevens ${ }^{8}$ and Joanne F. Dorgan ${ }^{1 *}$
}

\begin{abstract}
Introduction: During adolescence the breasts undergo rapid growth and development under the influence of sex hormones. Although the hormonal etiology of breast cancer is hypothesized, it remains unknown whether adolescent sex hormones are associated with adult breast density, which is a strong risk factor for breast cancer.

Methods: Percentage of dense breast volume (\%DBV) was measured in 2006 by magnetic resonance imaging in 177 women aged 25-29 years who had participated in the Dietary Intervention Study in Children from 1988 to 1997. They had sex hormones and sex hormone-binding globulin (SHBG) measured in serum collected on one to five occasions between 8 and 17 years of age. Multivariable linear mixed-effect regression models were used to evaluate the associations of adolescent sex hormones and SHBG with \%DBV.

Results: Dehydroepiandrosterone sulfate (DHEAS) and SHBG measured in premenarche serum samples were significantly positively associated with \%DBV (all $P_{\text {trend }} \leq 0.03$ ) but not when measured in postmenarche samples (all $P_{\text {trend }} \geq 0.42$ ). The multivariable geometric mean of $\%$ DBV across quartiles of premenarcheal DHEAS and SHBG increased from 16.7 to $22.1 \%$ and from 14.1 to $24.3 \%$, respectively. Estrogens, progesterone, androstenedione, and testosterone in pre- or postmenarche serum samples were not associated with \%DBV (all $P_{\text {trend }} \geq 0.16$ ).

Conclusions: Our results suggest that higher premenarcheal DHEAS and SHBG levels are associated with higher $\% D B V$ in young women. Whether this association translates into an increased risk of breast cancer later in life is currently unknown.
\end{abstract}

Clinical trials registration: ClinicalTrials.gov Identifier, NCT00458588 April 9, 2007; NCT00000459 October 27, 1999

\section{Introduction}

Breast density is a measure of the relative proportion of glandular and stromal tissue to fatty tissue in the breasts $[1,2]$ and is a strong risk factor for breast cancer [2]. Women with high breast density have a four- to sixfold increased risk of breast cancer [2]. Although reproductive and menstrual factors [3] and exogenous hormone use $[4,5]$ are positively associated with breast density, associations of endogenous sex hormones with breast density are inconsistent. Three [6-8] out of seven studies in premenopausal women [6-12] found no association between any of the sex hormones measured and

\footnotetext{
* Correspondence: jdorgan@som.umaryland.edu

1 Department of Epidemiology and Public Health, University of Maryland

School of Medicine, Howard Hall 102E, Baltimore, MD 21201, USA

Full list of author information is available at the end of the article
}

breast density, whereas others reported significant associations with estrogens $[8,10,12]$, progesterone [9], and sex hormone-binding globulin (SHBG) [10, 11]. Results for postmenopausal women $[8,13-23]$ are similarly conflicting and largely null.

Previous studies mainly enrolled middle-aged and older women. It remains unknown whether adolescent sex hormone levels are associated with breast density and breast cancer risk during adulthood. Adolescence is a time of rapid breast growth and development and increased susceptibility of breast tissue to carcinogens [24-26]. Modulating estrogen levels during puberty was reported to alter mammary ductal morphology in animal studies [27, 28]. Hormonal contraceptive use beginning at 12-17 years of age was associated with higher dense breast volume at 25-29 years of age than hormonal

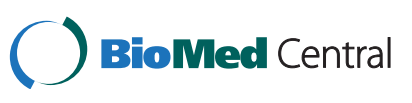

(c) 2015 Jung et al. This is an Open Access article distributed under the terms of the Creative Commons Attribution License (http://creativecommons.org/licenses/by/4.0), which permits unrestricted use, distribution, and reproduction in any medium, provided the original work is properly credited. The Creative Commons Public Domain Dedication waiver (http:// creativecommons.org/publicdomain/zero/1.0/) applies to the data made available in this article, unless otherwise stated. 
contraceptive use beginning at $22-28$ years [29]. In a pooled analysis, a longer reproductive period that was due to a younger age at menarche was associated with a larger increase in breast cancer risk than a longer reproductive period that was due to older age at menopause [30]. Collectively, the hormonal milieu during adolescence may be important in determining breast morphology and breast cancer risk.

To our knowledge, no prior study has evaluated associations between adolescent sex hormones and adult breast density, possibly because of few cohorts initiated at a young age. Therefore, we prospectively evaluated associations of adolescent serum sex hormones with breast density measured in young women in the Dietary Intervention Study in Children (DISC) and the DISC 2006 (DISC06) Follow-up Study [29, 31, 32].

\section{Methods}

\section{Study design and population}

DISC was a two-armed, multicenter, randomized, controlled clinical trial evaluating the efficacy and safety of a dietary intervention to reduce serum low-density lipoprotein cholesterol (LDL-C) in children [33, 34]. Between 1988 and 1990, 663 prepubertal children aged 7-10 years with elevated serum LDL-C were recruited at six clinical centers, and were randomized into two groups: a behavioral diet intervention group to reduce fat intake and a usual-care control group. In 1990, a hormone study ancillary to the DISC was initiated to assess the effect of the diet intervention on serum sex hormone levels [32, 35]. The intervention continued until 1997, when participants' mean age was 16.7 years [36]. From 2006 to 2008, the DISC06 Follow-up Study was conducted to assess the long-term effect of the diet intervention during childhood and adolescence on biomarkers associated with breast cancer risk [31].

Of the 301 female DISC participants, 286 had sex hormones measured at baseline or follow-up visits that took place at year 1, 3, 5 and last visits (approximately 7) years after randomization; none were pregnant or had used oral contraceptives within 3 months before blood collection [32]. Among these, 257 participated in the DISC06 Follow-up Study. We excluded women who were pregnant or breastfeeding at or within 12 weeks before the DISC06 follow-up visit, had breast augmentation or reduction surgery, or who had a technically unacceptable or missing magnetic resonance imaging (MRI) breast scan. Our final sample included a total of 177 women with breast density information and at least one measurement of adolescent serum sex hormones during the DISC trial; because of few measurements of sex hormones at baseline $(\mathrm{N}=38)$, baseline hormone data were only used for participants missing hormone data at the year 1 DISC visit.
For the DISC trial, assent from DISC participants and informed consent from parents and guardians were obtained. All participants in the DISC06 Follow-up Study provided informed consent. The institutional review boards at participating centers approved all DISC protocols (see the list of the institutional review boards in the acknowledgements).

\section{Data collection}

At all clinic visits during the DISC trial and a single clinic visit in the DISC06 Follow-up Study, participants completed questionnaires inquiring demographic and lifestyle information, medical and reproductive history, and medication use. Weight and height were measured using a standardized protocol [37]; body mass index (BMI) was calculated as weight $(\mathrm{kg}) /$ height $\left(\mathrm{m}^{2}\right)$. Diet was assessed by three nonconsecutive 24-hour dietary recalls over a 2-week period. Sexual maturation was assessed by Tanner stage [38] and onset of menses was ascertained annually during the DISC trial. We determined the days until the start of the next menses that corresponded to the date of blood collection from menstrual calendars completed by postmenarcheal participants for 6 weeks after their blood collections.

\section{Blood sampling}

At baseline and at year 1, 3, 5 and last follow-up visits in the DISC trial [32], a single blood sample was collected in the morning from participants who had fasted overnight. After standing at room temperature for $45 \mathrm{mi}-$ nutes to allow complete clotting, serum was separated by centrifugation, aliquoted into glass vials, and stored at $-70{ }^{\circ} \mathrm{C}$.

\section{Laboratory assays}

All laboratory assays were performed at Esoterix, Inc. (Calabasas Hills, CA, USA) using standard procedures. Steroid sex hormones were measured by radioimmunoassays (RIAs) following extraction (androstenedione, progesterone) and chromatography (estradiol, estrone, testosterone) or directly (dehydroepiandrosterone sulfate (DHEAS)) [39] Estrone sulfate and DHEAS were measured following enzymolysis as estrone and DHEA, respectively. SHBG was measured by an immunoradiometric assay [40]. Non-SHBG-bound estradiol concentration was calculated by multiplying the total estradiol concentration by the percentage of non-SHBG-bound estradiol measured by ammonium sulfate precipitation [41].

Analytical samples collected from the same clinic visit were assayed together in the same assay batches. Masked quality control (QC) samples that were aliquots from three serum QC pools were included in each batch [39]. The within-visit coefficients of variation (CV), estimated from QC samples, were 8-29 \% for estradiol, 12-31 \% 
for estrone, $12-17 \%$ for estrone sulfate, $4-10 \%$ for progesterone, 8-17 \% for androstenedione, 5-9 \% for DHEAS, 9-22 \% for testosterone, and $15 \%$ for SHBG. Low concentrations may have contributed to higher CVs for some hormones.

\section{Breast density measurement}

Breast density was measured using noncontrast MRI on a whole-body 1.5 Tesla or higher field-strength MRI scanner with a dedicated breast-imaging radiofrequency coil [37]. At all clinics, MRI technologists followed a common image acquisition protocol and were trained to recognize and correct failures caused by incomplete fat suppression, motion artifacts, and inadequate breast coverage. Sites were certified for MRI images following acceptable image quality on three volunteers. Dr. C. Klifa processed all MRI images using customized software to identify the chest wall-breast tissue boundary and skin surface and to separate breast fibroglandular and fatty tissue [42]. For images with incomplete or failed fat saturation, manual delineation was performed.

The total breast volume and absolute dense breast volume (ADBV), which quantifies fibroglandular tissue volume, were measured. The absolute nondense breast volume (ANDBV) was calculated by subtracting ADBV from total breast volume. The percentage of dense breast volume (\%DBV) was calculated as the ratio of ADBV to total breast volume. The density measures of both breasts were averaged for analysis. We considered \%DBV as primary outcome given the established association of mammographic \%DBV with breast cancer [43].

\section{Statistical analysis}

Breast density measures were initially described using nonparametric statistics, and prior to modeling were log-transformed to improve normality. Because hormone levels change during adolescence [44, 45], we standardized hormone data to have a comparable distribution across the DISC clinic visits. We first categorized hormone values into deciles based on the distribution of the hormone within each visit. Separately for visits that occurred before and after menarche, the visit-specific deciles of hormone concentrations were then regressed on predictors of adolescent hormone levels including age, BMI z-score, and visit number using a linear regression estimated by generalized estimating equations with an exchangeable correlation structure; after menarche, days until the start of the next menses was also included as a cubic spline. Residuals from these models were then added to the mean of the visit-specific decile to give standardized visit-specific deciles. These standardized visit-specific deciles were averaged for each participant separately for visits before and after menarche for the analysis of androgens and SHBG. For estrogens and progesterone postmenarche visits were further averaged separately for the follicular ( 0 or $>14$ days until start of next menses) and luteal (1-14 days until start of next menses) phase of the menstrual cycle. Higher quartiles of standardized sex hormone or SHBG values represent higher levels throughout the pre- or postmenarcheal periods.

We calculated the geometric mean of \%DBV, ADBV, and ANDBV and $95 \%$ confidence interval (CI) across quartiles of standardized hormone concentrations by exponentiating the coefficients from a multivariable linear mixed-effects regression model with robust standard errors [46]. The clinic was included as a random effect. The following potential confounders [29, 37, 47] were included as fixed effects: race, education level, treatment group, BMI at DISC06 follow-up, duration of hormonal contraceptive use, and parity (see Table 2 for categorization of covariates). Test for trend was from a Wald test using quartile medians. Tests for interaction by treatment assignment were conducted by including crossproduct terms in the fully adjusted models.

In sensitivity analyses, we conducted analyses stratified by DISC visit (baseline, syear 1 , year 3,5 , and the last trial visit), stages of breast development ( $\leq 3$ and $\geq 4)$, and treatment assignment (intervention and usual care). We also excluded participants with more than 33 days from blood draw to their next menses during the DISC trial and those using hormonal contraceptives at DISC06 follow-up visits.

Analyses were conducted using SAS (Cary, NC, USA) and STATA (College Station, TX, USA) statistical software. All tests were two sided. $P$ values $<0.05$ were considered statistically significant.

\section{Results}

Among 177 women available for analyses, the mean age was 27.1 years at the DISC06 follow-up visit (Table 1). The majority were white (91.5\%), nulliparous (71.2\%), and ever users of hormonal contraceptives (93.8 \%). The mean BMI was $25.4 \mathrm{~kg} / \mathrm{m}^{2}$. The mean age at menarche was 12.8 years. The median and interquartile range of \%DBV was 24.3 (9.7-41.2). The mean ages at blood collection were $10.2,12.1,14.2$, and 16.6 years at $\leq$ year 1 , year 3, year 5, and the last DISC trial visits, respectively. Additional information on lifestyle, diet, pubertal characteristics, and levels of sex hormones and SHBG during DISC trial visits is summarized in Table S1 in Additional file 1. All girls were prepubertal at baseline. Tanner stages of sexual maturation and the percentage of girls who were postmenarcheal gradually increased over the course of the trial; median levels of sex hormones varied accordingly. In contrast, BMI z-scores were similar across visits.

Tables 2 and 3 show associations of adult \%DBV with sex hormones and SHBG during adolescence adjusted 
Table 1 Participant characteristics $(N=177)$

\begin{tabular}{|c|c|c|}
\hline Characteristics & $N$ & Mean (SD) \\
\hline \multicolumn{3}{|l|}{ Age at blood collection during adolescence (yrs) } \\
\hline at $\leq 1$ year visit & 115 & $10.2(0.6)$ \\
\hline at year 3 visit & 167 & $12.1(0.60)$ \\
\hline at year 5 visit & 143 & $14.2(0.63)$ \\
\hline at last visit ${ }^{a}$ & 143 & $16.6(0.88)$ \\
\hline Age at breast MRI (yrs) & 177 & $27.1(1.01)$ \\
\hline BMI at breast MRI $\left(\mathrm{kg} / \mathrm{m}^{2}\right)$ & 177 & $25.4(5.38)$ \\
\hline Duration of hormonal contraceptive use (yrs) & 177 & $5.2(3.68)$ \\
\hline \multirow[t]{2}{*}{ Age at menarche (yrs) } & 177 & $12.9(1.26)$ \\
\hline & $N$ & Percentage \\
\hline \multicolumn{3}{|l|}{ Race } \\
\hline White & 162 & $91.5 \%$ \\
\hline Nonwhite & 15 & $8.5 \%$ \\
\hline \multicolumn{3}{|l|}{ Education } \\
\hline Bachelor's degree & 93 & $52.5 \%$ \\
\hline Graduate degree & 24 & $33.9 \%$ \\
\hline Other & 60 & $13.6 \%$ \\
\hline \multicolumn{3}{|l|}{ Number of pregnancies } \\
\hline 0 & 126 & $71.2 \%$ \\
\hline$\geq 1$ & 51 & $28.8 \%$ \\
\hline \multicolumn{3}{|l|}{ Family history of breast cancer } \\
\hline No & 167 & $96.5 \%$ \\
\hline Yes & 6 & $3.5 \%$ \\
\hline \multicolumn{3}{|l|}{ Hormonal contraceptive use } \\
\hline Never & 11 & $6.2 \%$ \\
\hline Former & 65 & $36.7 \%$ \\
\hline Current & 101 & $57.1 \%$ \\
\hline Breast density measures & $N$ & Median (IQR) \\
\hline Percent dense breast volume (\%) & 177 & $24.3(9.7-41.2)$ \\
\hline Absolute dense breast volume $\left(\mathrm{cm}^{3}\right)$ & 177 & $50.0(93.3-140.3)$ \\
\hline Absolute nondense breast volume $\left(\mathrm{cm}^{3}\right)$ & 177 & $299.2(157.8-484.9)$ \\
\hline
\end{tabular}

Abbreviations: SD standard deviation, MRI magnetic resonance imaging, $B M I$ body mass index, $I Q R$ interquartile range

a Last visit for blood collection occurred a median of 7 years after randomization in DISC

for adult BMI and other potential confounding factors. Results from the multivariable model without adult BMI were generally similar, possibly due to its high correlation with childhood BMI that is adjusted for when standardizing hormone data. DHEAS and SHBG concentrations before menarche were significantly positively associated with \%DBV. The multivariable adjusted geometric mean of \%DBV was $16.7 \%$ in women in the lowest quartile of premenarcheal DHEAS and $19.6 \%, 16.6 \%$, and $22.1 \%$ in women in the second, third, and highest quartile of premenarcheal DHEAS, respectively $\left(P_{\text {trend }}<0.001\right)$.
The multivariable geometric means of $\% \mathrm{DBV}$ in women increasing quartiles of premenarcheal SHBG quartiles were $14.4 \%$ to $18.7 \%, 18.3 \%$ and $24.3 \%\left(P_{\text {trend }}=0.03\right)$. In contrast, adolescent DHEAS and SHBG concentrations after menarche were not associated with adult \%DBV. Estrogen, progesterone, androstenedione, and testosterone concentrations in serum collected during adolescence before or after menarche were not associated with adult \%DBV. Results generally were similar when nonstandardized hormone levels measured separately at each clinic visit were examined in association with \%DBV (data not shown). An exception was follicular phase total and nonSHBG estradiol measured at the last DISC trial visit when women in the highest quartiles of these hormones had significantly lower \%DBV compared to women in the lowest quartiles. These associations were not consistently observed for postmenarcheal samples across clinic visits and could be due to chance.

In sensitivity analyses, excluding women who reported menstrual cycles longer than 33 days or who were parous did not change the results (data not shown). Restricting analyses to women not currently taking hormonal contraceptives at DISC06 visits did not change results substantially (data not shown). However, the positive association of premenarcheal SHBG with \%DBV was attenuated and no longer statistically significant, whereas the positive association of premenarcheal DHEAS with \%DBV became more linear; the geometric means of \%DBV across premenarcheal DHEAS quartiles (Q1-Q4) were $16.4 \%, 20.9 \%, 21.7 \%$ and $26.2 \%\left(P_{\text {trend }}=0.02\right)$. Treatment assignment did not significantly modify the association of pre- and postmenarcheal sex hormones and SHBG with \%DBV (all $P_{\text {interaction }} \geq 0.11$ ) except nonSHBG-bound estradiol $\left(P_{\text {interaction }}=0.03\right)$; however, nonSHBG-bound estradiol results were nonsignificant in either treatment group.

Because of hormonal changes with sexual maturation during adolescence $[44,45]$ (Table S1 in Additional file 1), we evaluated whether observed associations for DHEAS and SHBG with \%DBV varied in analyses stratified by Tanner stage of breast maturation. Consistent with results by menarche status at blood collection, DHEAS and SHBG concentrations in serum collected during adolescence at Tanner breast stages 1-3 were significantly positively associated with adult \%DBV, but concentrations in serum collected at breast stages 4 and 5 were not (data not shown).

Associations of sex hormones and SHBG with ADBV are shown in Tables S2 and S3 in Additional file 1 and their associations with ANDBV are shown in Table S4 and S5 in Additional file 1. Similar to \%DBV, premenarcheal DHEAS and SHBG were positively associated with ADBV, but these hormones were inversely associated with ANDBV. Even so, none of the hormones or 
Table 2 Multivariate ${ }^{a}$-adjusted geometric mean and $95 \%$ confidence interval (Cl) for percent dense breast volume by quartiles of estrogens and progesterone at pre $^{\mathrm{b}}$ and postmenarcheal ${ }^{\mathrm{c}}$ period

\begin{tabular}{|c|c|c|c|c|c|c|}
\hline \multirow{3}{*}{ Quartiles } & \multicolumn{2}{|c|}{ Premenarche } & \multicolumn{4}{|c|}{ Postmenarche } \\
\hline & \multirow[b]{2}{*}{ Mean } & \multirow[b]{2}{*}{$(95 \%$ Cl) } & \multicolumn{2}{|c|}{ Follicular phase $^{d}$} & \multicolumn{2}{|c|}{ Luteal phase $^{d}$} \\
\hline & & & Mean & $(95 \% \mathrm{Cl})$ & Mean & $(95 \% \mathrm{Cl})$ \\
\hline Estradiol & & $N=153$ & & $N=110$ & & $N=88$ \\
\hline Q1 & 17.3 & $(11.1-21.0)$ & 17.1 & $(11.7-25.0)$ & 16.7 & $(11.6-23.9)$ \\
\hline Q2 & 18.3 & $(12.4-27.0)$ & 23.6 & $(19.8-28.1)$ & 15.3 & $(10.7-21.9)$ \\
\hline Q3 & 17.6 & $(14.6-21.2)$ & 15.0 & $(10.3-21.8)$ & 19.4 & $(15.2-24.8)$ \\
\hline Q4 & 21.5 & $(18.9-24.4)$ & 17.5 & $(13.8-22.2)$ & 17.8 & $(12.4-25.6)$ \\
\hline P-trend ${ }^{e}$ & 0.26 & & 0.42 & & 0.43 & \\
\hline Non-SHBG-bound estradiol & & $N=151$ & & $N=106$ & & $N=88$ \\
\hline Q1 & 17.8 & $(12.1-26.2)$ & 17.6 & $(13.5-23.0)$ & 18.2 & $(12.7-26.2)$ \\
\hline Q2 & 20.3 & $(14.0-29.6)$ & 22.7 & $(16.1-32.2)$ & 12.3 & $(10.5-14.3)$ \\
\hline Q3 & 16.3 & $(11.7-22.9)$ & 14.9 & $(12.6-17.7)$ & 22.0 & $(17.8-27.2)$ \\
\hline Q4 & 19.6 & $(16.6-23.1)$ & 17.7 & $(13.2-23.8)$ & 18.0 & $(13.1-24.8)$ \\
\hline$P$-trend ${ }^{e}$ & 0.78 & & 0.24 & & 0.43 & \\
\hline Estrone & & $N=153$ & & $N=110$ & & $N=88$ \\
\hline Q1 & 18.1 & $(12.3-26.6)$ & 15.5 & $(12.1-19.8)$ & 16.2 & $(13.5-20.9)$ \\
\hline Q2 & 18.0 & $(14.0-23.2)$ & 19.7 & $(13.1-29.7)$ & 17.2 & $(10.1-29.4)$ \\
\hline Q3 & 21.4 & $(15.3-29.8)$ & 18.3 & $(14.5-23.0)$ & 17.4 & $(11.9-25.4)$ \\
\hline Q4 & 17.1 & $(13.0-22.5)$ & 18.8 & $(14.3-24.8)$ & 17.6 & $(12.6-24.5)$ \\
\hline$P$-trend ${ }^{e}$ & 0.93 & & 0.43 & & 0.71 & \\
\hline Estrone sulfate & & $N=146$ & & $N=110$ & & $N=88$ \\
\hline Q1 & 21.2 & $(14.8-30.4)$ & 19.3 & $(12.3-30.1)$ & 19.4 & $(13.9-27.0)$ \\
\hline Q2 & 15.2 & $(9.9-23.5)$ & 14.9 & $(12.1-18.2)$ & 13.8 & $(12.2-15.8)$ \\
\hline Q3 & 15.7 & $(11.1-22.2)$ & 15.7 & $(12.2-20.3)$ & 18.7 & $(14.3-24.4)$ \\
\hline Q4 & 22.5 & $(18.9-26.9)$ & 23.4 & $(21.2-25.8)$ & 17.7 & $(13.1-23.8)$ \\
\hline$P$-trend ${ }^{e}$ & 0.79 & & 0.49 & & 0.73 & \\
\hline Progesterone & & & & $N=110$ & & $N=84$ \\
\hline Q1 & - & & 17.0 & $(11.0-24.8)$ & 16.4 & $(14.4-18.6)$ \\
\hline Q2 & - & & 21.0 & $(17.0-26.2)$ & 16.7 & $(13.1-21.3)$ \\
\hline Q3 & - & & 16.5 & $(12.9-24.4)$ & 19.5 & $(11.5-33.1)$ \\
\hline Q4 & - & & 15.8 & $(13.6-18.8)$ & 17.6 & $(11.2-27.8)$ \\
\hline$P$-trend ${ }^{e}$ & & & 0.81 & & 0.38 & \\
\hline
\end{tabular}

Abbreviations: $\mathrm{Cl}$ confidence interval, SHBG sex hormone-binding globulin

${ }^{a}$ Geometric means and $95 \% \mathrm{Cl}$ are estimated from linear mixed-effects models including clinic as a random effect and adjusted for treatment group (diet intervention group, usual-care control group), BMI ( $\mathrm{kg} / \mathrm{m}^{2}$, continuous), parity ( 0 and $\left.>0\right)$, duration of hormone use (yrs, continuous), race (white and nonwhite), and education (bachelor's degree, graduate school and other) as fixed effects

${ }^{\text {b} T h e ~ p r e m e n a r c h e a l ~ e s t r o g e n ~ l e v e l s ~ w e r e ~ s t a n d a r d i z e d ~ b y ~ a d j u s t i n g ~ f o r ~ a g e ~ a t ~ v i s i t, ~ B M I ~ z-s c o r e ~ a t ~ v i s i t, ~ a n d ~ v i s i t ~ n u m b e r ~ i n ~ y e a r s ~ a f t e r ~ r a n d o m i z a t i o n ~ b y ~ r e s i d u a l ~}$ method

'The postmenarcheal estrogens and progesterone levels were standardized by adjusting for age at visit, BMI z-score at visit, visit number in years after randomization and days from blood draw to start of next menses as a cubic spline by residual method

d. Days 1 through 14 before next menses were defined as luteal, whereas days 0 and greater than 14 were defined as follicular e $P$-test for trend was conducted by modeling the quartile medians of standardized hormone concentrations as a continuous term in linear mixed-effects models and calculating the Wald test statistic

SHBG measured before menarche was significantly associated with ADBV or ANDBV. In contrast, estradiol in serum collected during adolescence after menarche in the luteal phase of the menstrual cycle was significantly positively associated with ANDBV $\left(P_{\text {trend }}=\right.$ 0.02); the geometric mean ANDBV increased from 294.5 to $336.0 \mathrm{~cm}^{3}$ between the lowest and highest estradiol quartiles. 
Table 3 Multivariate ${ }^{a}$-adjusted geometric mean and 95\% confidence interval $(\mathrm{Cl})$ for percent dense breast volume by quartiles of androgens and SHBG at pre- ${ }^{\mathrm{b}}$ and postmenarcheal ${ }^{\mathrm{b}}$ periods

\begin{tabular}{|c|c|c|c|c|c|c|}
\hline \multirow[t]{2}{*}{ Quartiles } & \multicolumn{2}{|c|}{ Premenarche } & \multicolumn{2}{|c|}{ Postmenarche } & \multicolumn{2}{|c|}{ All periods } \\
\hline & Mean & $(95 \% \mathrm{Cl})$ & Mean & $(95 \%$ Cl) & Mean & $(95 \% \mathrm{Cl})$ \\
\hline \multicolumn{2}{|c|}{ Androstenedione } & $N=153$ & & $N=154$ & & $N=174$ \\
\hline Q1 & 20.2 & $(17.2-23.7)$ & 17.9 & $(14.6-22.1)$ & 19.2 & $(16.5-22.3)$ \\
\hline Q2 & 18.8 & $(14.9-23.8)$ & 19.4 & $(14.8-25.5)$ & 19.2 & $(14.7-24.9)$ \\
\hline Q3 & 18.1 & $(13.5-24.1)$ & 18.0 & $(14.4-22.3)$ & 18.0 & $(15.2-21.3)$ \\
\hline Q4 & 17.4 & $(11.0-27.6)$ & 17.9 & $(13.7-23.5)$ & 18.6 & $(14.1-24.6)$ \\
\hline P-trend ${ }^{c}$ & 0.30 & & 0.88 & & 0.69 & \\
\hline DHEAS & & $N=153$ & & $N=156$ & & $N=176$ \\
\hline Q1 & 16.7 & $(12.7-22.0)$ & 19.9 & $(13.6-29.1)$ & 18.7 & $(14.2-24.5)$ \\
\hline Q2 & 19.6 & $(14.2-26.9)$ & 16.3 & $(12.1-22.1)$ & 17.5 & $(14.6-20.9)$ \\
\hline Q3 & 16.6 & $(13.2-20.9)$ & 17.0 & $(14.5-20.0)$ & 17.5 & $(15.1-20.3)$ \\
\hline Q4 & 22.1 & $(17.3-28.0)$ & 20.3 & $(17.9-22.9)$ & 21.5 & $(18.2-15.4)$ \\
\hline P-trend ${ }^{c}$ & $<0.001$ & & 0.84 & & 0.10 & \\
\hline \multicolumn{2}{|l|}{ Testosterone } & $N=150$ & & $N=156$ & & $N=175$ \\
\hline Q1 & 17.6 & $(14.8-20.9)$ & 16.7 & $(14.1-19.7)$ & 18.5 & (15.2-22.6) \\
\hline Q2 & 20.5 & $(18.4-22.7)$ & 18.6 & $(14.8-23.3)$ & 19.2 & $(16.3-22.7)$ \\
\hline Q3 & 18.0 & $(12.0-26.9)$ & 18.2 & $(12.5-26.4)$ & 18.7 & $(14.7-23.8)$ \\
\hline Q4 & 17.7 & $(11.5-27.2)$ & 19.8 & $(17.4-22.6)$ & 18.2 & $(14.1-23.6)$ \\
\hline P-trend ${ }^{c}$ & 0.90 & & 0.16 & & 0.87 & \\
\hline SHBG & & $N=153$ & & $N=156$ & & $N=176$ \\
\hline Q1 & 14.4 & $(10.2-20.4)$ & 15.7 & $(11.0-22.6)$ & 15.5 & $(12.8-18.7)$ \\
\hline Q2 & 18.7 & $(15.3-22.8)$ & 17.1 & $(12.9-22.7)$ & 17.5 & $(13.3-23.1)$ \\
\hline Q3 & 18.3 & $(14.6-22.9)$ & 25.0 & $(18.0-24.6)$ & 22.1 & $(20.2-24.2)$ \\
\hline Q4 & 24.3 & $(19.6-30.1)$ & 16.7 & (14.8-18.8) & 20.5 & $(15.6-26.9)$ \\
\hline P-trend ${ }^{c}$ & 0.03 & & 0.42 & & 0.05 & \\
\hline
\end{tabular}

Abbreviations: $\mathrm{Cl}$ confidence interval, DHEAS, dehydroepiandrosterone sulfate; $S H B G$, sex hormone-binding globulin

${ }^{a}$ Geometric means and $95 \% \mathrm{Cl}$ are estimated from linear mixed-effects models including clinic as a random effect and adjusted for treatment group (diet intervention group, usual-care control group, $\mathrm{BMI}\left(\mathrm{kg} / \mathrm{m}^{2}\right.$, continuous), parity $(0$ and $>0)$, duration of hormone use (yrs, continuous), race (white and nonwhite), and education (bachelor's degree, graduate school and other) as fixed effects

${ }^{\mathrm{b}}$ The androgens and SHBG levels were standardized by adjusting for age at visit, BMI z-score at visit, and visit number in years after randomization by residual method

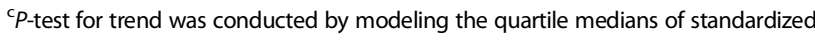
hormone concentrations as a continuous term in linear mixed-effects models and calculating the Wald test statistic

\section{Discussion}

In this study examining adolescent sex hormones in relation to young adult breast density, DHEAS and SHBG levels during adolescence before, but not after, menarche were significantly positively associated with adult $\% \mathrm{DBV}$. Estrogens, progesterone, androstenedione, and testosterone levels during adolescence were not significantly associated with adult $\% \mathrm{DBV}$.
It is largely unknown whether adolescent sex hormones levels predict breast cancer development later in life. Nonetheless, the breast undergoes rapid growth and development during adolescence [24, 25]. Animal and experimental studies suggest that DNA damage coupled with insufficient DNA repair during childhood or adolescence may induce epigenetic and translational modifications that have persistent effects in the breasts [48, 49]. Indeed, oral contraceptive use during teenage years $[29,50]$ or before pregnancy [51] was associated with higher breast tissue proliferation rates [51], higher dense breast volume [29], and elevated breast cancer risk [50].

To our knowledge, this is the first epidemiologic study that directly related adolescent sex hormone levels with adult breast density. Previous studies used sex hormone data collected from middle-aged and older women [6-21]. The association between premenarcheal DHEAS and adult \%DBV in our study was nonlinearly positive. In analysis restricted to participants not using hormonal contraceptives at DISC06 visits when breast density was measured, \%DBV increased monotonically across increasing quartiles of premenarcheal DHEAS from $16.4 \%$ to $20.9 \%, 21.7 \%$, and $26.2 \%$. Thus, even though we adjusted for duration of hormone use in our multivariable model, our nonlinear results might be due to residual confounding by current hormone use. This positive association is consistent with results from one study of premenopausal women [10]. Our findings for postmenarcheal DHEAS concentrations are similar to those from most studies in older women that reported relatively flat associations [12-14, 21].

The breast matures mostly before menarche under the influence of sex hormones and growth factors, and DHEAS may have its greatest effect on breast morphology at this time of expansion of the breast ductal architecture. DHEAS can be metabolized to estrogens and has been shown to have estradiol-like proliferative effects in a low-estrogen environment [52], typical of childhood and early puberty [53]. In young girls approaching puberty, prior to activation of the hypothalamic-pituitaryovarian (HPO) axis, adrenal androgens including DHEAS can be metabolized to estrogens in adipose tissue [54]. Peripheral conversion of adrenal androgens to estrogens may explain earlier breast development independent of changes in ovarian hormones in recent birth cohorts [55] and isolated breast development that occurs without activation of the HPO in some girls [56]. DHEAS is also positively associated with growth factors during adolescence [57] that may partly regulate breast development [58-60].

Our significant positive association between premenarcheal SHBG levels and adult \%DBV is consistent with some studies of premenopausal $[6,10,11]$ and postmenopausal women $[8,13,23]$, while others reported a suggestive, but nonsignificant positive $[17,61]$ or null association $[14,16,18,21]$. Although SHBG is generally thought to 
modulate availability of estradiol to cells, recent discoveries of cell surface SHBG receptors and intracellular SHBG in the breast suggest that SHBG could potentially influence breast density via other mechanisms [62]. Alternatively, given that $\mathrm{BMI}$ is negatively correlated with breast density [63] and SHBG, our results could be due to residual confounding by BMI even though we adjusted for both childhood and adulthood BMI. This result could also be due to chance.

Notably, breast density was significantly positively associated with DHEAS and SHBG before menarche, but not after menarche. Although few prior data exist to explain our results, breast tissue typically starts to develop around 9 years of age and matures near the onset of menarche $[24,55,64,65]$. Interestingly, in a recent large prospective cohort study, earlier thelarche (the initiation of breast development) and a longer duration between thelarche and menarche were significantly positively associated with breast cancer risk later in life [66]. The breast's susceptibility to endogenous and possibly exogenous exposures might vary over adolescence.

Irrespective of menarche status, other sex hormones measured during adolescence were not significantly associated with adult breast density in our study, which is consistent with the largely null results reported for estrogens [8-12, 67], progesterone [8, 9, 12, 67], testosterone $[10-12,14,16-18,20,22,67,68]$ and androstenedione $[10,13,14,18,21]$ in adult women. But these hormones are primarily secreted from the ovary. Ovulatory cycles normally become stable 5 years past menarche [69], and prepubertal and early pubertal girls have relatively low ovarian hormone levels, particularly estradiol [53]. RIAs that we used to measure serum hormone levels may not be sensitive and specific enough to quantify physiologically relevant levels during early adolescence $[53,70]$. The limit of detection for estradiol and estrone was $0.5 \mathrm{ng} / \mathrm{dL}$ and $43 \%$ of girls at $\leq 1$ year visits had estradiol levels at or below this level.

A strength of our study is the prospective design of enrolling prepubertal children, and following them to their late 20s. With repeated measurements of sex hormones, we could examine sex hormones at different stages of puberty. MRI avoids exposing participants to ionizing radiation and measures breast density not impaired by the high parenchymal breast density typical of young women [71]. Even so, breast density as measured by MRI or mammography is highly correlated $(r>0.75)$ $[72,73]$, and breast density, assessed by a volumetric method or by mammography, is similarly positively associated with breast cancer risk [2, 74]. Given the natural involution of breast with aging [75], breast density measured at 25-29 years old, as in our study, might be the most relevant marker of the effect of adolescent sex hormones on the breasts, if any. Staff trained to follow a standardized protocol collected detailed information on body size, lifestyle, reproductive, and menstrual characteristics during both adolescence and adulthood, which enabled us to control for potential confounding factors.

Our study had limitations. Despite the cyclic variation of estrogens and progesterone after the onset of menarche, postmenarcheal samples were not collected timed to the menstrual cycle. Even so, luteal and follicular phase estrogens and progesterone were analyzed separately, and days until start of next menses were taken into account in analyses. Circulating sex hormone levels are an indirect marker of breast tissue exposure, but their associations with breast cancer risk indicate serum levels are a meaningful measure of exposure [76, 77]. Participants were slightly heavier with elevated LDL-C levels than the general population during childhood [33, 34], possibly limiting generalizability of our results. Sample size was relatively small. Results should be interpreted with caution because multiple tests were conducted. Finally, there is possibility of unknown residual confounding.

\section{Conclusions}

In conclusion, circulating levels of premenarche DHEAS and SHBG were significantly positively associated with \%DBV. Associations with other adolescent sex hormones were not detected. Our results suggest that differences in sex hormones during adolescence may be relevant to breast morphology during adulthood. Large studies that measure hormones using highly sensitive and specific mass spectrometry that can detect lower levels of circulating hormones in children and adolescent are warranted.

\section{Additional file}

Additional file 1: Supplementary tables S1-S5.

\begin{abstract}
Abbreviations
ADBV: absolute dense breast volume; ANDBV: absolute nondense breast volume; BMI: body mass index; Cl: confidence interval; $\mathrm{CV}$ : coefficient of variation; \%DBV: percentage dense breast volume;

DHEAS: dehydroepiandrosterone sulfate; DISC: Dietary Intervention Study in Children; DISC06: Dietary Intervention Study in Children 2006 Follow-up Study; HPO: hypothalamic-pituitary-ovarian; IQR: interquartile range; LDL-C: low-density lipoprotein cholesterol; MRI: magnetic resonance imaging; QC: quality control; RIA: radioimmunoassay; SD: standard deviation; SHBG: sex hormone-binding globulin.
\end{abstract}

\section{Competing interests}

The authors declare that they have no competing interests.

\section{Authors' contributions}

SJ analyzed and interpreted the data and wrote the manuscript. JFD conceived of the study design, secured funding, contributed to the interpretation, and critically reviewed the manuscript. BLE provided statistical expertise and contributed the interpretation of data. DWC measured sex hormone level. NMH and CCK quantified \%DBV and ADBV from MRI images. JAS, ESL, FZS, KP, LVH, NLL, LGS, and VJS participated in study design and data collection. All authors read and approved the final manuscript. 


\section{Acknowledgements}

This work was supported by US National Institutes of Health $(\mathrm{NIH})$ grants (R03 CA167764 to J.F. Dorgan, R01 CA104670 to J.F. Dorgan, R01 CA116182 to N.M. Hylton, and P30 CA134274 to K.J. Cullen). We thank the institutional review board at Maryland Medical Research Institute, University of Maryland Baltimore, MD, Fox Chase Cancer Center, Philadelphia, PA and the following six clinical centers: Children's Hospital, New Orleans, LA; Johns Hopkins University Hospital, Baltimore, MD; Kaiser Permanente Center for Health Research, Portland, OR; University of Medicine and Dentistry of New Jersey, Newark, NJ; Northwestern University Medical School, Chicago, IL; and University of lowa Hospital and Clinics, lowa City, IA. We are grateful to all participants in the DISC06 study and collaborators for their invaluable contributions.

\section{Author details}

'Department of Epidemiology and Public Health, University of Maryland School of Medicine, Howard Hall 102E, Baltimore, MD 21201, USA. ${ }^{2}$ Fox Chase Cancer Center, 333 Cottman Avenue, Philadelphia, PA 19111, USA. ${ }^{3}$ Esoterix Inc, 4301 Lost Hills Road, Calabasas Hills, CA 91301, USA. ${ }^{4}$ Department of Preventive Medicine, Feinberg School of Medicine, Northwestern University, 303 E Chicago Avenue, Chicago, IL 60611, USA. ${ }^{5}$ Department of Radiology, University of California, San Francisco, 500 Parnassus Avenue, San Francisco, CA 94143, USA. ${ }^{6}$ Dangeard Group, 580 W Remington Drive, San Francisco, CA 94087, USA. ${ }^{7}$ Department of Medicine, Rutgers New Jersey Medical School, 185 S Orange Avenue, Newark, NJ 07103, USA. ${ }^{8}$ Kaiser Permanente Center for Health Research, $3800 \mathrm{~N}$ Interstate Avenue, Portland, OR 97227, USA. ${ }^{9}$ Department of Pediatrics, Louisiana State University School of Medicine, 1901 Perdido Street, New Orleans, LA 70112, USA. ${ }^{10}$ Department of Epidemiology, University of lowa, 200 Hawkins Drive, lowa City, IA 52242, USA. ${ }^{11}$ Department of Obstetrics and Gynecology, University of Southern California Keck School of Medicine, 1975 Zonal Avenue, Los Angeles, CA 90033, USA.

\section{Received: 28 January 2015 Accepted: 13 May 2015} Published online: 04 June 2015

\section{References}

1. Boyd NF, Martin L, Yaffe MJ, Minkin S. Mammographic density and breast cancer risk: current understanding and future prospects. Breast Cancer Res. 2011;13:223.

2. McCormack VA, dos Santos SI. Breast density and parenchymal patterns as markers of breast cancer risk: a meta-analysis. Cancer Epidemiol Biomarkers Prev. 2006;15:1159-69.

3. Vachon CM, Kuni CC, Anderson K, Anderson VE, Sellers TA. Association of mammographically defined percent breast density with epidemiologic risk factors for breast cancer (United States). Cancer Causes Control. 2000;11:653-62.

4. McTiernan A, Martin CF, Peck JD, Aragaki AK, Chlebowski RT, Pisano ED, et al. Estrogen-plus-progestin use and mammographic density in postmenopausal women: Women's Health Initiative randomized trial. J Natl Cancer Inst. 2005;97:1366-76

5. Greendale GA, Reboussin BA, Slone S, Wasilauskas C, Pike MC, Ursin G. Postmenopausal hormone therapy and change in mammographic density. J Natl Cancer Inst. 2003;95:30-7.

6. Chen JH, Chen WP, Chan S, Yeh DC, Su MY, McLaren CE. Correlation of endogenous hormonal levels, fibroglandular tissue volume and percent density measured using 3D MRI during one menstrual cycle. Ann Oncol. 2013;24:2329-35.

7. Meyer F, Brisson J, Morrison AS, Brown JB. Endogenous sex hormones, prolactin, and mammographic features of breast tissue in premenopausal women. J Natl Cancer Inst. 1986;77:617-20.

8. Boyd NF, Stone J, Martin LJ, Jong R, Fishell E, Yaffe M, et al. The association of breast mitogens with mammographic densities. Br J Cancer. 2002;87:876-82.

9. Noh JJ, Maskarinec G, Pagano I, Cheung LW, Stanczyk FZ. Mammographic densities and circulating hormones: a cross-sectional study in premenopausal women. Breast (Edinburgh, Scotland). 2006;15:20-8.

10. Yong M, Atkinson C, Newton KM, Aiello Bowles EJ, Stanczyk FZ, Westerlind $\mathrm{KC}$, et al. Associations between endogenous sex hormone levels and mammographic and bone densities in premenopausal women. Cancer Causes Control. 2009;20:1039-53.

11. Borugian MJ, Spinelli JJ, Gordon PB, Abanto Z, Brooks-Wilson A, Pollak MN, et al. Fasting insulin and endogenous hormones in relation to premenopausal breast density (Canada). Cancer Causes Control. 2014;25:385-94.
12. Walker K, Fletcher O, Johnson N, Coupland B, McCormack VA, Folkerd E, et al. Premenopausal mammographic density in relation to cyclic variations in endogenous sex hormone levels, prolactin, and insulin-like growth factors. Cancer Res. 2009;69:6490-9.

13. Bremnes Y, Ursin G, Bjurstam N, Rinaldi S, Kaaks R, Gram IT. Endogenous sex hormones, prolactin and mammographic density in postmenopausal Norwegian women. Int J Cancer. 2007;121:2506-11.

14. Verheus M, Peeters PH, van Noord PA, van der Schouw YT, Grobbee DE, van Gils $\mathrm{CH}$. No relationship between circulating levels of sex steroids and mammographic breast density: the Prospect-EPIC cohort. Breast Cancer Res. 2007;9:R53.

15. Johansson H, Gandini S, Bonanni B, Mariette F, Guerrieri-Gonzaga A, Serrano $D$, et al. Relationships between circulating hormone levels, mammographic percent density and breast cancer risk factors in postmenopausal women. Breast Cancer Res Treat. 2008;108:57-67.

16. McCormack VA, Dowsett M, Folkerd E, Johnson N, Palles C, Coupland B, et al. Sex steroids, growth factors and mammographic density: a crosssectional study of UK postmenopausal Caucasian and Afro-Caribbean women. Breast Cancer Res. 2009;11:R38.

17. Sprague BL, Trentham-Dietz A, Gangnon RE, Buist DS, Burnside ES, Bowles EJ, et al. Circulating sex hormones and mammographic breast density among postmenopausal women. Horm Cancer. 2011;2:62-72.

18. Woolcott CG, Courneya KS, Boyd NF, Yaffe MJ, McTiernan A, Brant R, et al. Association between sex hormones, glucose homeostasis, adipokines, and inflammatory markers and mammographic density among postmenopausal women. Breast Cancer Res Treat. 2013;139:255-65.

19. Aiello EJ, Tworoger SS, Yasui Y, Stanczyk FZ, Potter J, Ulrich CM, et al. Associations among circulating sex hormones, insulin-like growth factor, lipids, and mammographic density in postmenopausal women. Cancer Epidemiol Biomarkers Prev. 2005;14:1411-7.

20. Greendale GA, Palla SL, Ursin G, Laughlin GA, Crandall C, Pike MC, et al. The association of endogenous sex steroids and sex steroid binding proteins with mammographic density: results from the Postmenopausal Estrogen/Progestin Interventions Mammographic Density Study. Am J Epidemiol. 2005;162:826-34.

21. Tamimi RM, Hankinson SE, Colditz GA, Byrne C. Endogenous sex hormone levels and mammographic density among postmenopausal women. Cancer Epidemiol Biomarkers Prev. 2005;14:2641-7.

22. Schoemaker MJ, Folkerd EJ, Jones ME, Rae M, Allen S, Ashworth A, et al. Combined effects of endogenous sex hormone levels and mammographic density on postmenopausal breast cancer risk: results from the Breakthrough Generations Study. Br J Cancer. 2014;110:1898-907.

23. Warren R, Skinner J, Sala E, Denton E, Dowsett M, Folkerd E, et al. Associations among mammographic density, circulating sex hormones, and polymorphisms in sex hormone metabolism genes in postmenopausal women. Cancer Epidemiol Biomarkers Prev. 2006;15:1502-8.

24. Biro FM, Greenspan LC, Galvez MP, Pinney SM, Teitelbaum S, Windham GC, et al. Onset of breast development in a longitudinal cohort. Pediatrics. 2013;132:1019-27.

25. Russo J, Russo $\|_{\text {. }}$. Breast development, hormones and cancer. Adv Exp Med Biol. 2008;630:52-6.

26. Colditz GA, Frazier AL. Models of breast cancer show that risk is set by events of early life: prevention efforts must shift focus. Cancer Epidemiol Biomarkers Prev. 1995;4:567-71.

27. Dewi FN, Wood CE, Lees CJ, Willson CJ, Register TC, Tooze JA, et al. Dietary soy effects on mammary gland development during the pubertal transition in nonhuman primates. Cancer Prev Res (Phila). 2013;6:832-42.

28. Dearth RK, Hiney JK, Srivastava VK, Hamilton AM, Dees WL. Prepubertal exposure to elevated manganese results in estradiol regulated mammary gland ductal differentiation and hyperplasia in female rats. Exp Biol Med. 2014;239:871-82.

29. Dorgan JF, Klifa C, Deshmukh S, Egleston BL, Shepherd JA, Kwiterovich Jr PO, et al. Menstrual and reproductive characteristics and breast density in young women. Cancer Causes Control. 2013;24:1973-83.

30. Collaborative Group on Hormonal Factors in Breast Cancer. Menarche, menopause, and breast cancer risk: individual participant meta-analysis, including 118964 women with breast cancer from 117 epidemiological studies. Lancet Oncol. 2012;13:1141-51.

31. Dorgan JF, Liu L, Klifa C, Hylton N, Shepherd JA, Stanczyk FZ, et al. Adolescent diet and subsequent serum hormones, breast density, and bone mineral density in young women: results of the Dietary Intervention Study in Children. Cancer Epidemiol Biomarkers Prev. 2010;19:1545-56. 
32. Dorgan JF, Hunsberger SA, McMahon RP, Kwiterovich Jr PO, Lauer RM, Van Horn L, et al. Diet and sex hormones in girls: findings from a randomized controlled clinical trial. J Natl Cancer Inst. 2003;95:132-41.

33. Writing Group for the DISC Collaborative Research Group. Efficacy and safety of lowering dietary intake of fat and cholesterol in children with elevated low-density lipoprotein cholesterol. The Dietary Intervention Study in Children (DISC). JAMA. 1995;273:1429-35.

34. DISC Collaborative Research Group. Dietary intervention study in children (DISC) with elevated low-density-lipoprotein cholesterol. Design and baseline characteristics. Ann Epidemiol. 1993;3:393-402.

35. Dorgan JF, McMahon RP, Friedman LA, Van Horn L, Snetselaar LG, Kwiterovich Jr PO, et al. Diet and sex hormones in boys: findings from the dietary intervention study in children. J Clin Endocrinol Metab. 2006;91:3992-6.

36. Obarzanek E, Kimm SY, Barton BA, Van Horn LL, Kwiterovich Jr PO, SimonsMorton DG, et al. Long-term safety and efficacy of a cholesterol-lowering diet in children with elevated low-density lipoprotein cholesterol: sevenyear results of the Dietary Intervention Study in Children (DISC). Pediatrics. 2001;107:256-64

37. Dorgan JF, Klifa C, Shepherd JA, Egleston BL, Kwiterovich Jr PO, Himes JH, et al. Height, adiposity and body fat distribution and breast density in young women. Breast Cancer Res. 2012;14:R107.

38. Tanner JM. Growth at adolescence. 2nd ed. Oxford (UK): Blackwell Scientific; 1962.

39. Dorgan JF, Fears TR, McMahon RP, Aronson Friedman L, Patterson BH, Greenhut SF. Measurement of steroid sex hormones in serum: a comparison of radioimmunoassay and mass spectrometry. Steroids. 2002;67:151-8.

40. Dorgan JF, Baer DJ, Albert PS, Judd JT, Brown ED, Corle DK, et al. Serum hormones and the alcohol-breast cancer association in postmenopausal women. J Natl Cancer Inst. 2001:93:710-5.

41. Nankin HR, Pinto R, Fan DF, Troen P. Daytime titers of testosterone, LH, estrone, estradiol, and testosterone-binding protein: acute effects of $\mathrm{LH}$ and LH-releasing hormone in men. J Clin Endocrinol Metab. 1975;41:271-81.

42. Klifa C, Carballido-Gamio J, Wilmes L, Laprie A, Lobo C, Demicco E, et al. Quantification of breast tissue index from MR data using fuzzy clustering. Conference Proc IEEE Eng Med Biol Soc. 2004;3:1667-70.

43. Pettersson A, Graff RE, Ursin G, Santos Silva ID, McCormack V, Baglietto L, et al. Mammographic density phenotypes and risk of breast cancer: a metaanalysis. J Natl Cancer Inst. 2014;106:5.

44. Sizonenko PC. Endocrinology in preadolescents and adolescents. I. Hormonal changes during normal puberty. Am J Dis Child. 1978;132:704-12.

45. Root AW. Endocrinology of puberty. I. Normal sexual maturation. J Pediatr. 1973;83:1-19.

46. Littell RC. SAS for mixed models. 2nd ed. Cary, NC: SAS Institute; 2006.

47. Adami H-O, Hunter DJ, Trichopoulos D. Textbook of Cancer Epidemiology, vol. 36, 2nd edn. Oxford, New York: Oxford University Press; 2008.

48. Fenton SE, Reed C, Newbold RR. Perinatal environmental exposures affect mammary development, function, and cancer risk in adulthood. Annu Rev Pharmacol Toxicol. 2012;52:455-79.

49. Hilakivi-Clarke L, de Assis S, Warri A. Exposures to synthetic estrogens at different times during the life, and their effect on breast cancer risk. J Mammary Gland Biol Neoplasia. 2013;18:25-42.

50. Jernstrom H, Loman N, Johannsson OT, Borg A, Olsson H. Impact of teenage oral contraceptive use in a population-based series of early-onset breast cancer cases who have undergone BRCA mutation testing. Eur J Cancer. 2005;41:2312-20

51. Anderson TJ, Battersby S, King RJ, McPherson K, Going JJ. Oral contraceptive use influences resting breast proliferation. Hum Pathol. 1989;20:1139-44.

52. Ebeling P, Koivisto VA. Physiological importance of dehydroepiandrosterone. Lancet. 1994;343:1479-81.

53. Bay K, Andersson AM, Skakkebaek NE. Estradiol levels in prepubertal boys and girls-analytical challenges. Int J Androl. 2004;27:266-73.

54. Biro FM, Pinney SM, Huang B, Baker ER, Walt Chandler D, Dorn LD. Hormone changes in peripubertal girls. J Clin Endocrinol Metab. 2014;99:3829-35

55. Aksglaede L, Sorensen K, Petersen JH, Skakkebaek NE, Juul A. Recent decline in age at breast development: the Copenhagen Puberty Study. Pediatrics. 2009;123:e932-9.

56. Ahmed ML, Ong KK, Dunger DB. Childhood obesity and the timing of puberty. Trends Endocrinol Metab. 2009;20:237-42.
57. Guercio G, Rivarola MA, Chaler E, Maceiras M, Belgorosky A. Relationship between the growth hormone/insulin-like growth factor-I axis, insulin sensitivity, and adrenal androgens in normal prepubertal and pubertal girls. J Clin Endocrinol Metab. 2003;88:1389-93.

58. Ibanez L, Valls C, Ong K, Dunger DB, de Zegher F. Metformin therapy during puberty delays menarche, prolongs pubertal growth, and augments adult height: a randomized study in low-birth-weight girls with early-normal onset of puberty. J Clin Endocrinol Metab. 2006;91:2068-73.

59. Kleinberg DL, Ruan W. IGF-I, GH, and sex steroid effects in normal mammary gland development. J Mammary Gland Biol Neoplasia. 2008;13:353-60.

60. Sternlicht MD. Key stages in mammary gland development: the cues that regulate ductal branching morphogenesis. Breast Cancer Res. 2006;8:201.

61. Greendale GA, Reboussin BA, Sie A, Singh HR, Olson LK, Gatewood O, et al. Effects of estrogen and estrogen-progestin on mammographic parenchymal density. Postmenopausal Estrogen/Progestin Interventions (PEPI) Investigators. Ann Intern Med. 1999;130:262-9.

62. Rosner W, Hryb DJ, Kahn SM, Nakhla AM, Romas NA. Interactions of sex hormone-binding globulin with target cells. Mol Cell Endocrinol. 2010;316:79-85.

63. Andersen ZJ, Baker JL, Bihrmann K, Vejborg I, Sorensen TI, Lynge E. Birth weight, childhood body mass index, and height in relation to mammographic density and breast cancer: a register-based cohort study. Breast Cancer Res. 2014;16:R4.

64. Cabrera SM, Bright GM, Frane JW, Blethen SL, Lee PA. Age of thelarche and menarche in contemporary US females: a cross-sectional analysis. J Pediatr Endocrinol Metab. 2014;27:47-51.

65. Tanner JM. Issues and advances in adolescent growth and development. J Adolesc Health Care. 1987;8:470-8.

66. Bodicoat DH, Schoemaker MJ, Jones ME, McFadden E, Griffin J, Ashworth A, et al. Timing of pubertal stages and breast cancer risk: the Breakthrough Generations Study. Breast Cancer Res. 2014;16:R18.

67. Boyd N, Martin L, Chavez S, Gunasekara A, Salleh A, Melnichouk O, et al. Breast-tissue composition and other risk factors for breast cancer in young women: a cross-sectional study. Lancet Oncol. 2009;10:569-80.

68. Tamimi RM, Byrne C, Colditz GA, Hankinson SE. Endogenous hormone levels, mammographic density, and subsequent risk of breast cancer in postmenopausal women. J Natl Cancer Inst. 2007;99:1178-87.

69. Vihko R, Apter D. Endocrine characteristics of adolescent menstrual cycles: impact of early menarche. J Steroid Biochem. 1984;20:231-6.

70. Rosner W, Auchus RJ, Azziz R, Sluss PM, Raff H. Position statement: Utility, limitations, and pitfalls in measuring testosterone: an Endocrine Society position statement. J Clin Endocrinol Metab. 2007;92:405-13.

71. Kerlikowske K, Grady D, Barclay J, Sickles EA, Ernster V. Effect of age, breast density, and family history on the sensitivity of first screening mammography. JAMA. 1996;276:33-8.

72. Wei J, Chan HP, Helvie MA, Roubidoux MA, Sahiner B, Hadjiiski LM, et al. Correlation between mammographic density and volumetric fibroglandular tissue estimated on breast MR images. Med Phys. 2004;31:933-42.

73. Thompson DJ, Leach MO, Kwan-Lim G, Gayther SA, Ramus SJ, Warsi I, et al. Assessing the usefulness of a novel MRI-based breast density estimation algorithm in a cohort of women at high genetic risk of breast cancer: the UK MARIBS study. Breast Cancer Res. 2009;11:R80.

74. Shepherd JA, Kerlikowske K, Ma L, Duewer F, Fan B, Wang J, et al. Volume of mammographic density and risk of breast cancer. Cancer Epidemiol Biomarkers Prev. 2011;20:1473-82

75. Milanese TR, Hartmann LC, Sellers TA, Frost MH, Vierkant RA, Maloney SD, et al. Age-related lobular involution and risk of breast cancer. J Natl Cancer Inst. 2006;98:1600-7.

76. Key T, Appleby P, Barnes I, Reeves G. Endogenous sex hormones and breast cancer in postmenopausal women: reanalysis of nine prospective studies. J Natl Cancer Inst. 2002;94:606-16.

77. Key TJ, Appleby PN, Reeves GK, Travis RC, Alberg AJ, Barricarte A, et al. Sex hormones and risk of breast cancer in premenopausal women: a collaborative reanalysis of individual participant data from seven prospective studies. Lancet Oncol. 2013;14:1009-19. 